\title{
Randomised clinical trial of an intensive intervention in the primary care setting of patients with high plasma fibrinogen in the primary prevention of cardiovascular disease
}

Juan José Rodríguez Cristóbal ${ }^{*}$, Carlos Alonso-Villaverde Grote ${ }^{2}$, Pere Travé Mercadé ${ }^{3}$, José Ma Pérez Santos ${ }^{1}$, Esther Peña Sendra ${ }^{2}$, Anna Muñoz Lloret ${ }^{4}$, Cristina Fernández Pérez ${ }^{5}$ and Domingo Bleda Fernández ${ }^{6}$, for The EFAP group

\begin{abstract}
Background: We have studied the possible effects of an intensive lifestyle change program on plasma fibrinogen levels, in patients with no cardiovascular disease, with elevated levels of fibrinogen, normal cholesterol levels, and a moderate estimated risk of coronary heart disease (CHD) and we have also analysed whether the effect on fibrinogen is independent of the effect on lipids.

Results: This clinical trial was controlled, unblinded and randomized, with parallel groups, done in 13 Basic Health Areas (BHA) in l'Hospitalet de Llobregat (Barcelona) and Barcelona city. The study included 436 patients, aged between 35 and 75 years, with no cardiovascular disease, elevated levels of fibrinogen (> $300 \mathrm{mg} / \mathrm{dl}$ ), cholesterol $<250 \mathrm{mg} / \mathrm{dl}$, 218 of whom received a more intensive intervention consisting of advice on lifestyle and treatment. The follow-up frequency of the intervention group was every 2 months. The other 218 patients followed their standard care in the BHAs. Fibrinogen, plasma cholesterol and other clinical biochemistry parameters were assessed.

The evaluation of the baseline characteristics of the patients showed that both groups were homogenous. Obesity and hypertension were the most prevalent risk factors. After 24 months of the study, statistically significant changes were seen between the adjusted means of the two groups, for the following parameters: fibrinogen, plasma cholesterol, systolic and diastolic blood pressure and body mass index.

Conclusion: Intensive intervention to achieve lifestyle changes has shown to be effective in reducing some of the estimated CHD factors. However, the effect of intensive intervention on plasma fibrinogen levels did not correlate with the variations in cholesterol.
\end{abstract}

Trial Registration: ClinicalTrials.gov: NCT01089530

Keywords: Fibrinogen, Cholesterol, Cardiovascular risk factors, Primary prevention

\section{Background}

This manuscript is a translation of our already published manuscript [1]. Fibrinogen can be considered an independent cardiovascular risk factor (CVRF) [2,3]. However, several studies have shown a correlation between cholesterol (CT) and fibrinogen levels [4]. Also it has

\footnotetext{
* Correspondence: 21002jrc@comb.es

'Medicina, Area Básica Salud Florida Sud, Parc dels Ocellets, L'Hospitalet del Llobregat, Barcelona, Spain

Full list of author information is available at the end of the article
}

been argued that the elevated levels of fibrinogen may be influenced by environmental factors, diet, smoking, excess weight and physical exercise [5]. Various clinical and epidemiological studies have described the implications of the elevated plasma fibrinogen values as CVRF in coronary, cerebral disease and peripheral arteries. The Northwick Park Heart study describes a relationship between high values of plasma fibrinogen and the risk of coronary ischemia [6]. In REGICOR study [7], it was described as an average of fibrinogen of $2.92 \mathrm{~g} / \mathrm{l}$ in

\section{Ciomed Central}


males and $3.09 \mathrm{~g} / \mathrm{l}$ in women, the plasmatic value of fibrinogen being highest in the subset of smoking patients. The study published by Gil et al. [8], described an intervention study done in a primary care setting, in patients with an average age of 72.6 years and with several CVRF; the prevalence of hyperfibrinogenemia was found to be $26.5 \%$. Other studies in younger patients with an average age of 57 and clinical manifestations of cardiovascular disease, have found a prevalence of $60 \%$ $[9,10]$. In different epidemiological studies, such as the Yano et al. [11], an increase in cardiovascular morbidity and mortality has been shown in patients with fibrinogen levels above $300 \mathrm{mg} / \mathrm{dl}$.

Lifestyle interventions make a notable impact on some of the modifiable CVRF; in spite of this, there are not many studies who have analysed the effects of these modifications (smoking cessation, diet and physical exercise) on fibrinogen levels. In addition, these studies have been conducted in settings different from ours, and mostly at short term $[5,6]$. Because of this, we have designed a study of intervention, in the primary care setting, to assess the effect on the fibrinogen levels in a subset of patients with intensive intervention (in frequency and intensity) on changes in their lifestyle, as compared to a control group, according to the usual intervention practiced in the basic areas of health (BHA). The study has been done in patients with fibrinogen levels $>300 \mathrm{mg} / \mathrm{dl}$, total cholesterol $<250 \mathrm{mg} / \mathrm{dl}$ and an estimated moderate or high CHD risk according to Framingham [12], adjusted according to fibrinogen levels $[12,13]$ and had a follow up period of 2 years on each subject.

\section{Aims}

Primary aim To evaluate the effect of an intensive intervention to modify lifestyle (hypo caloric diet, smoking cessation and physical exercise) in the fibrinogen levels in patients without cardiovascular disease with hyperfibrinogenemia (> $300 \mathrm{mg} / \mathrm{dl}$ ), total cholesterol levels less than $250 \mathrm{mg} / \mathrm{dl}$ and an estimated moderate or high CHD risk.

\section{Secondary aim}

(a) To assess the effect of this intensive intervention in some of the modifiable Cardiovascular Risk Factors.

(b) To confirm that this effect is independent of the variations of the total cholesterol levels.

\section{Methods}

We designed a randomized, controlled clinical trial, parallel groups, consisting of 436 patients, divided into two groups: a) an intensive intervention group, both in the frequency and intensity of their changes in lifestyle, b) a control group, receiving the standard therapy. The protocol has been described in a previous publication [14]. The study was approved by Jordi Gol I Gurina EECC.

Inclusion criteria

- Patients of both genders, aged between 30 and 75 years, in which in two consecutive analyses, separated by a minimum interval of 15 days, with fibrinogen levels $>300 \mathrm{mg} / \mathrm{dl}$ and plasma total cholesterol $<250 \mathrm{mg} / \mathrm{dl}$.

- Agreement to participate in the study, with written informed consent using procedures reviewed and approved by the EECC review board.

Exclusion criteria

- Any lipid-lowering therapy (dietary or pharmacological intervention).

- Local or generalized infection, either acute or chronic.

- History of cardiovascular disease, according to medical records and/or anamnesis.

- Fibrinogen lowering therapies (ticlopidine, fibrates, pentoxifylline)

- Severe clinical pathology (terminally ill patients, dementia, etc.)

\section{Sample size calculation}

We have assumed that:

1. The prevalence of smoking, overweight, obesity and sedentarism in the study population are 28,48 and $84 \%$ [7], respectively.

2. The effectiveness of common interventions are: $[5,13]$

- Giving Up Smoking Advice: 38\%.

- Dietary recommendations for overweight/obese patients: $20 \%$.

- Increase physical activity recommendations in sedentary patients: $30 \%$.

3. Smoking cessation and regular physical activity (measured by means of one unit of sporting activity) reduces, on average, fibrinogen levels by $0.4 \mathrm{~g} / \mathrm{l}$, and a diet of 1,000-1,400 cal/day reduces mean fibrinogen from 3 to $2.8 \mathrm{~g} / \mathrm{l}$ [5], during a complete follow up of one year.

Taking into account the prevalence of the cardiovascular risk factors described, the effectiveness of these interventions, its impact on fibrinogen levels and assuming an additive effect of all of them, we aim to achieve a mean reduction of fibrinogen of $17.2 \mathrm{mg} / \mathrm{dl}$, after a complete follow up of one year.

4. Intensive intervention will get an average reduction of fibrinogen levels twice as much as the standard one, i.e. a reduction of $34.4 \mathrm{mg} / \mathrm{dl}$, during a follow up of one year.

5. An alpha risk of $5 \%, 80 \%$ (1-beta) power and that the standard deviation of fibrinogen is $55 \mathrm{mg} / \mathrm{dl}$ [5]. 
6. A percentage of $20 \%$ withdrawals.

Considering all these assumptions, the study was planned to include more than 436 patients.

\section{Randomisation}

Patients meeting the inclusion and exclusion criteria listed above were selected consecutively from those visited by the participating investigators.

\section{Random allocation sequence}

A blocked random allocation sequence was centrally generated by an statistician.

Blocks contained six participants, so that three of them will receive the usual intervention and three the intensive intervention. The order of assigned interventions within each block was randomised. When a investigator received the informed consent of a patient, he phoned a member of the research team, who assigned participants to the corresponding intervention.

\section{Description of the groups}

Control group. This subset of patients have received advice about their lifestyle (diet, exercise and smoking cessation) according to the practice guidelines of the 'Institut Català de la Salut'(ICS), following nernational consensus $[12,15]$.

Intervention group. An active follow up of this group of patients was done, consisting of:

- Phone calls to get psychologist support, and letters to record each visit with the physician, additional measures to encourage the maintenance of lifestyle modifications, which will be done every 2 months. In each visit, physical activity questionnaires were done, as well as both pharmacological medical recommendations and lifestyle changes [15-17]. A laboratory analysis was done every 8 months (Table 1 ).

\section{Blinding}

Due to the nature of the study, patients and physicians allocated to the intervention group were aware of the allocated arm. However, outcome assessors and data analysts were kept blinded to the allocation.

Definitions and methods of measurement of outcome variables:

Administrative data: complete name, address and telephone number, name of the medical center of primary care, medical history, number of medical record, date of registration, date of birth and sex. Toxic history: smoking habits (daily consumption of tobacco in number of cigarettes), alcohol consumption (g/day).
Pathological history: Arterial hypertension (HBP), diabetes mellitus (DM), dislipaemia, overweight/obesity, chronic obstructive pulmonary disease.

Physical examination: weight $(\mathrm{kg})$, size $(\mathrm{cm})$, Body Mass Index (BMI) $(\mathrm{kg} / \mathrm{m} 2)$, Systolic Blood Pressure (SBP) and Diastolic Blood Pressure (DBP).

Physical activity: classification of the patient, according to the intensity of their physical activity: active, partially active or inactive.

Analytical data: Fibrinogen, Total cholesterol, High density lipoprotein cholesterol (HDL-C) Low density lipoprotein cholesterol (LDL-C), triglycerides, glucose, uric acid, Hematocrit (\%), white blood cells and platelets.

Collection data and analysis: design of a data collection form, on which is listed data identification, variables of the study and the frequency of visits.

All patients provided written informed consent.

\section{Statistical analysis}

The initial characteristics of both groups have been compared by means of bivariate techniques: $\chi 2$ test, in the case of proportions, and $t$ Student test, in case of means. Analysis of Covariance was used to calculate the effect of the kind of intervention the final fibrinogen adjusted to the total cholesterol values.

To analyze the possible association between the type of intervention (dichotomous qualitative variable) and response variable (plasmatic fibrinogen levels, quantitative variable), Covariance analysis (ANCOVA) will be used. This statistical technique allows us to obtain 2 regression lines, parallel, that correlates the results of fibrinogen levels post intervention with the individual baseline, in each group of intervention, without a possible influence of the fibrinogen level values pre or post intervention between the 2 groups. This technique is also used to verify that the effect of the intervention in the final fibrinogen levels is independent of the final total cholesterol variations.

\section{Results}

39 of the 624 patients at baseline decided not to participate, 19 were excluded because they did not meet inclusion criteria and 130 have an inappropriate laboratory analysis.

Of the remaining patients that met inclusion criteria, 438 were randomized and assigned to one of the 2 groups, and followed for a 2 year period. At the end of the 2 years, 72 were lost in the intensive intervention group, 64 in the standard intervention group, (Figure 1). The percentage of patients lost in the follow up was similar for the 2 groups. 
Table 1 Treatment of patients with intensive intervention

\begin{tabular}{|c|c|c|c|c|}
\hline & Definition & Objectives & Intervention & Periodicity \\
\hline Smoking & $\begin{array}{l}\text { People who has } \\
\text { smoked daily, any } \\
\text { amount of cigarettes, } \\
\text { over the last month. }\end{array}$ & $\begin{array}{l}\text { Smoking } \\
\text { cessation }\end{array}$ & $\begin{array}{l}\text { Smoking history } \\
\text { Degree of dependency } \\
\text { Motivation to give up smoking } \\
\text { Clear and tailored } \\
\text { advice } \\
\text { A follow-up program } \\
\text { for those patients who } \\
\text { stop smoking } \\
\text { Use of TSN or } \\
\text { bupropion }\end{array}$ & 2 months \\
\hline \multirow[t]{2}{*}{$\begin{array}{l}\text { Physical } \\
\text { activity }\end{array}$} & $\begin{array}{l}\text { Among the activities } \\
\text { that people do over a } \\
24 \mathrm{~h} \text { period, } \\
\text { occupational related } \\
\text { practices, leisure and } \\
\text { free time are the } \\
\text { most important ones. }\end{array}$ & $\begin{array}{l}\text { Increase the } \\
\text { physical } \\
\text { activity }\end{array}$ & $\begin{array}{l}\text { Interview about } \\
\text { physical activities and } \\
\text { classify: active, } \\
\text { partially active or } \\
\text { sedentary. }\end{array}$ & 2 months \\
\hline & & & $\begin{array}{l}\text { Advice to start, } \\
\text { increase or sustain } \\
\text { physical activities. }\end{array}$ & \\
\hline $\begin{array}{l}\text { Obesity, } \\
\text { overweight }\end{array}$ & $\begin{array}{l}\text { Body mass index } \\
\text { (BMI) BMI > } 30 \\
\mathrm{~kg} / \mathrm{m}^{2}=\text { obesity } 25- \\
30 \mathrm{~kg} / \mathrm{m}^{2}= \\
\text { overweight }\end{array}$ & $\begin{array}{l}\mathrm{IMC} 20-25 \\
\mathrm{~kg} / \mathrm{m}^{2}\end{array}$ & $\begin{array}{l}\text { Gradual weight loss } \\
0.51 \mathrm{~kg} \text { per week } \\
\text { Advice healthy diet } \\
\text { once objectives are } \\
\text { achieved }\end{array}$ & 2 months \\
\hline Hypertension & $\begin{array}{l}\mathrm{SBP} \geq 140 \mathrm{mmHg} \\
\text { and/or } \mathrm{DBP} \geq 90 \\
\mathrm{mmHg}\end{array}$ & $\begin{array}{l}\mathrm{PA}<140 / 90 \\
\mathrm{mmHg} \\
\text { Diabetics BP }< \\
130 / 80 \mathrm{mmHg}\end{array}$ & $\begin{array}{l}\text { Dietary measures or } \\
\text { pharmacological } \\
\text { treatment, according to } \\
\text { guidelines }\end{array}$ & 2 months \\
\hline $\begin{array}{l}\text { Diabetes } \\
\text { mellitus }\end{array}$ & $\begin{array}{l}\text { Two basal glycemias } \\
\text { in venous serum } \geq \\
126 \mathrm{mg} / \mathrm{dl}\end{array}$ & $\mathrm{HbA}_{1 \mathrm{C}}<7 \%$ & $\begin{array}{l}\text { Dietary measures or } \\
\text { pharmacological } \\
\text { treatment according to } \\
\text { guidelines }\end{array}$ & 2 months \\
\hline
\end{tabular}

$\mathrm{HbA}_{1 \mathrm{C}}$ glycated hemoglobin, BP blood pressure; SBP BP systolic diastolic; SBP diastolic blood pressure; TSN replacement therapy with nicotine

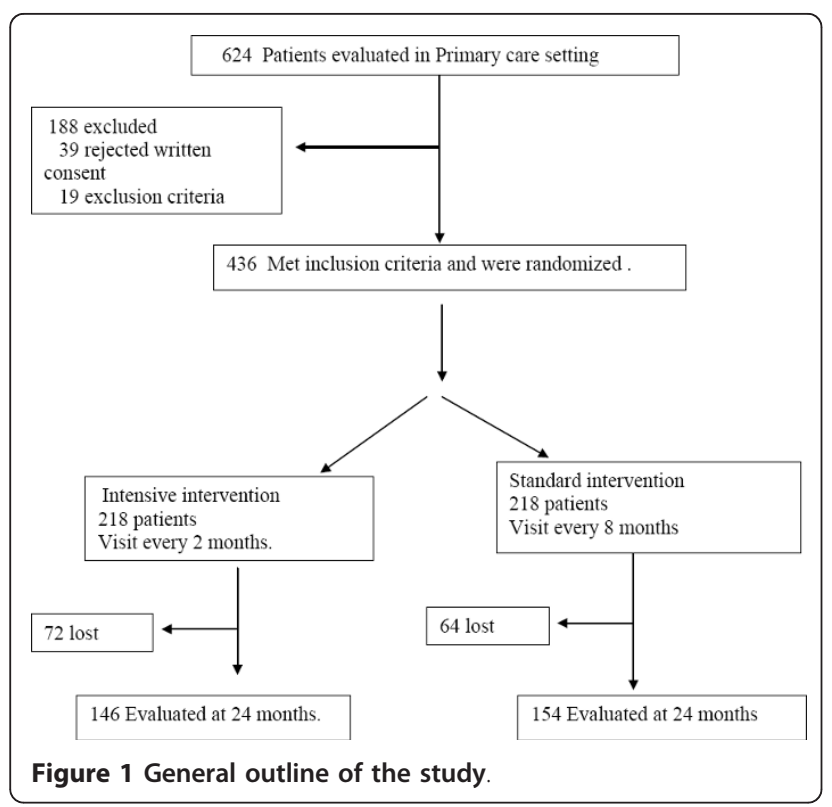

Table 2 describes the initial baseline characteristics of the population assigned to each group. Both groups were homogenous, with neither statistically significant nor clinically relevant differences between them. The percentage of individuals who smoked was somewhat higher in the Group of intensive intervention (31.9\%) as compared to the standard group (26.8\%), while in this last group the number of diabetic patients is slightly larger $(15.1 \%$ versus $11.9 \%)$.

Regarding the presence of cardiovascular risk factors, the prevalence of obesity and hypertension were, respectively, 55.5 and $41.4 \%$ in the standard group, and 46.8 and $42.7 \%$ in the intensive intervention group.

Table 3 shows the results of the analysis per protocol of the main outcomes of the study, according to the type of intervention, after a 2 year follow-up. When analyzing fibrinogen levels, we could find a difference 31.0 $\mathrm{mg} / \mathrm{dl}$ between the mean adjusted fibrinogen levels, showing a statistically significant $(\mathrm{p}<0.001)$ difference in favour of the intensive intervention. We could also see statistically significant differences in favour of 
Table 2 Baseline characteristics of participants depending on the type intervention assigned*

\begin{tabular}{|c|c|c|}
\hline & $\begin{array}{c}\text { Standard } \\
\text { intervention } \\
(n=154)\end{array}$ & $\begin{array}{c}\text { Intensive } \\
\text { intervention } \\
(n=146)\end{array}$ \\
\hline Women, n (\%) & $98(63.6)$ & $92(63.0)$ \\
\hline Men, $n(\%)$ & $56(36.4)$ & $54(37.0)$ \\
\hline Age in years & $58.6 \pm 10.6$ & $56.8 \pm 10.6$ \\
\hline Fibrinogen, mg/dl & $368.7 \pm 64.5$ & $364.9 \pm 59.4$ \\
\hline Total cholesterol, mg/dl & $210.2 \pm 25.5$ & $211.1 \pm 26.7$ \\
\hline Tryglicerides, mg/dl & $116.6 \pm 59.6$ & $116.5 \pm 54.3$ \\
\hline $\mathrm{cHDL}, \mathrm{mg} / \mathrm{dl}$ & $55.2 \pm 13.1$ & $54.2 \pm 12.0$ \\
\hline $\mathrm{cLDL}, \mathrm{mg} / \mathrm{dl}$ & $134.3 \pm 28.6$ & $134.6 \pm 26.9$ \\
\hline Basal glucose, mg/dl & $108.3 \pm 33.1$ & $108.5 \pm 35.9$ \\
\hline Hematocrit, $\%$ & $42.0 \pm 3.7$ & $42.1 \pm 3.4$ \\
\hline Leucocytes, $10 \mathrm{e}^{12} / /$ & $7.6 \pm 3.0$ & $7.4 \pm 2.0$ \\
\hline Platelets, $10 \mathrm{e}^{9} / \mathrm{I}$ & $243.0 \pm 60.2$ & $252.3 \pm 67.6$ \\
\hline Weight, kg & $76.7 \pm 12.9$ & $75.7 \pm 13.1$ \\
\hline Height, cm & $158.7 \pm 8.4$ & $158.7 \pm 9.8$ \\
\hline $\mathrm{SBP}, \mathrm{mmHg}$ & $134.7 \pm 18.0$ & $133.8 \pm 17.4$ \\
\hline $\mathrm{DBP}, \mathrm{mmHg}$ & $81.7 \pm 9.4$ & $80.7 \pm 9.8$ \\
\hline $\mathrm{BMI}, \mathrm{kg} / \mathrm{m}^{2}$ & $30.5 \pm 5.1$ & $30.3 \pm 5.8$ \\
\hline Obesity, (\%) & $(55.5 \%)$ & $(46.8 \%)$ \\
\hline Tobacco, (\%) & $(26.8 \%)$ & (31.9\%) \\
\hline Hipertensión arterial(\%) & $(41.4 \%)$ & $(42.7 \%)$ \\
\hline Diabetes mellitus(\%) & $(15.1 \%)$ & $(11.9 \%)$ \\
\hline $\begin{array}{l}\mathrm{HbA} 1 \mathrm{c} \% \text { in diabetic } \\
\text { patients }\end{array}$ & $6.9 \pm(1.7)$ & $7.1 \pm(1.5)$ \\
\hline
\end{tabular}

*The values represent mean \pm standard deviation, except those in bold, representing number of patients (percentage)

CHDL high density lipoprotein cholesterol,

$C L D L$ low density lipoprotein cholesterol;

$S B P$ systolic blood pressure;

$D B P$ diastolic blood pressure;

$B M I$ body mass index;

HbA1C glycated haemoglobin

intensive intervention between the adjusted final total cholesterol, SBP, DBP and BMI.

Table 4 shows the result of the 'per protocol evaluation' of 'tobacco consumption' variable according to the type of intervention. The difference in the proportion of smokers at the end the study is statistically significant as compared to the initial for each type of intervention, although we didn't find any significant differences between the proportions of smokers in groups at the end of the study.

Figure 2 shows the relationship between the fibrinogen levels and total cholesterol at the end of the study, according to type of intervention. The Covariance analysis done has not shown any statistically significant relationship between the fibrinogen levels and the total cholesterol at the end of the study.

\section{Discussion}

Baseline demographics did not differ significantly between the 2 groups (Table 2).

The prevalence of some of the cardiovascular risk factors, such as hypertension, diabetes mellitus and smoking are similar to other population studies carried out in our environment $[15,18]$. However, obesity, in our study, has shown a higher prevalence, possibly due to the characteristics of the population included: patients who visited their physician, mean average age of 57 years, and an estimated moderate or high cardiovascular risk, different from the usual care setting. These results confirms what other investigators have found in relation to obesity $[19,20]$, that it is becoming a major health problem, and desirable implement innovative strategies to prevent and treat it are urgently need.

The lifestyle modification- intensive intervention group, at the end of a 2 years of follow-up period, showed a significant reduction of the weight and BMI, as compared to the standard intervention group.

The results of our patients confirm data from other studies [20,21], showing that lifestyle changes are effective in patients with overweight and obesity.

After 24 months of follow-up, we found a reduction statistically significant of total cholesterol, fibrinogen levels, SBP, DBP and BMI in the intensive intervention group, and showing no differences in other analyzed variables.

These results are similar to the ones found in a study done in 20 centers in a primary care setting in United Kingdom [21], which assessed the effectiveness of the motivational interview to modify the intake of fat, physical activity, SBP and DBP, as well as tobacco consumption in 883 patients with risk high cardiovascular disease. It was obtained a benefit in the intervention group, but these changes could not be neither controlled nor related to the changes achieved in fibrinogen levels.

It is well known that one of the tables used to calculate the estimated cardiovascular risk in primary prevention are tables of Framingham [22,23]. Some authors [13] have proposed to adjust the obtained risk according to fibrinogen levels.

In our study, the fibrinogen levels values in the intensive- intervention group were decreased an average of $31 \mathrm{mg} / \mathrm{dl}$. This would mean that, in the case of a male patient with a $330 \mathrm{mg} / \mathrm{dl}$ fibrinogen level, considered an estimated high risk calculated by adjusted Framingham tables by the plasma figures and received intensive intervention, could move to a moderate risk and, therefore, change the therapeutic goal.

\section{Conclusions}

In our study, intensive intervention of lifestyle modifications have been shown effective to reduce some major 
Table 3 Results of the per protocol analysis after 2 years of follow-up.

\begin{tabular}{|c|c|c|c|c|c|}
\hline $\begin{array}{l}\text { Outcome } \\
\text { measure }\end{array}$ & $\begin{array}{c}\text { Intensive } \\
\text { intervention } \\
(\mathrm{n}=154) \text { mean } \pm \\
\text { SD }\end{array}$ & $\begin{array}{c}\text { Standard } \\
\text { intervention } \\
(\mathrm{n}=146) \text { mean } \pm \\
\text { SD }\end{array}$ & $\begin{array}{l}\text { Adjusted } \\
\text { difference } \\
\text { mean* }\end{array}$ & $95 \% \mathrm{Cl}$ & $p$ value \\
\hline Fibrinogen $^{\S}$ & $306.3 \pm 57.9$ & $337.6 \pm 68.8$ & 31.0 & $17.0-45.0$ & 0.0001 \\
\hline Total cholesterol & $204.4 \pm 30.5$ & $224.4 \pm 32.0$ & 19.2 & $12.7-25.6$ & 0.0001 \\
\hline $\mathrm{CHDL}$ & $61.7 \pm 15.1$ & $60.3 \pm 14.6$ & 2.1 & -0.9 to 51 & 0.171 \\
\hline CLDL & $131.1 \pm 28.0$ & $129.6 \pm 31.4$ & -19 & -9.9 to 6.0 & 0.633 \\
\hline Triglycerides & $115.1 \pm 56.5$ & $119.2 \pm 55.4$ & 5.6 & -7.4 to 18.6 & 0.394 \\
\hline SBP & $129.6 \pm 15.1$ & $136.9 \pm 14.8$ & 6.8 & 2.8-10.7 & 0.0001 \\
\hline DBP & $75.5 \pm 9.7$ & $80.4 \pm 8.7$ & 4.4 & $2.0-6.8$ & 0.0001 \\
\hline BMI & $29.6 \pm 4.8$ & $31.8 \pm 4.9$ & 1.7 & $1.1-2.2$ & 0.0001 \\
\hline HbA1C (diabetic patients) & $7.2 \pm 1.7$ & $7.7 \pm 1.3$ & 0.5 & -0.5 to 1.6 & 0.340 \\
\hline
\end{tabular}

depending on the type of intervention. All comparisons of outcome scores between interventions groups are presented as the difference in means after adjusting for baseline outcome measures

* Difference between groups using covariance analysis after adjusting for baseline outcome measure. Positive values favour intensive intervention

$\S$ is an independent variable

$S D$ standard deviation; $C$ c confidence interval; $C H D L$ high density cholesterol lipoprotein; $C L D L$ low density lipoprotein cholesterol; SBP systolic blood pressure; $D B P$ diastolic blood pressure; BMI body mass index; HbA1C glycated haemoglobin

Table 4 Results of the per protocol analysis after two years of follow-up according to type of intervention for the variable 'tobacco consumption'

\begin{tabular}{|c|c|c|c|c|}
\hline Proportion of smokers & Intensive intervention & Standard intervention & Difference of proportions & $p$ value $^{a}$ \\
\hline Before & $31.9 \%$ & $26.8 \%$ & $5.1 \%$ & 0.372 \\
\hline After & $19.4 \%$ & $22.1 \%$ & $2.7 \%$ & 0.669 \\
\hline Before-after difference & $12.5 \%$ & $4.7 \%$ & & \\
\hline $95 \% \mathrm{Cl}$ & 7. $0-18.2$ & $1.0-8.4$ & & \\
\hline$p$ value & 0.016 & 0.0001 & & \\
\hline
\end{tabular}

Cl confidence interval

a Difference between groups, calculated by means of $X^{2}$ (comparison of proportions in independent groups)

b Difference between groups calculated using McNemar test (comparison of proportions with paired data)

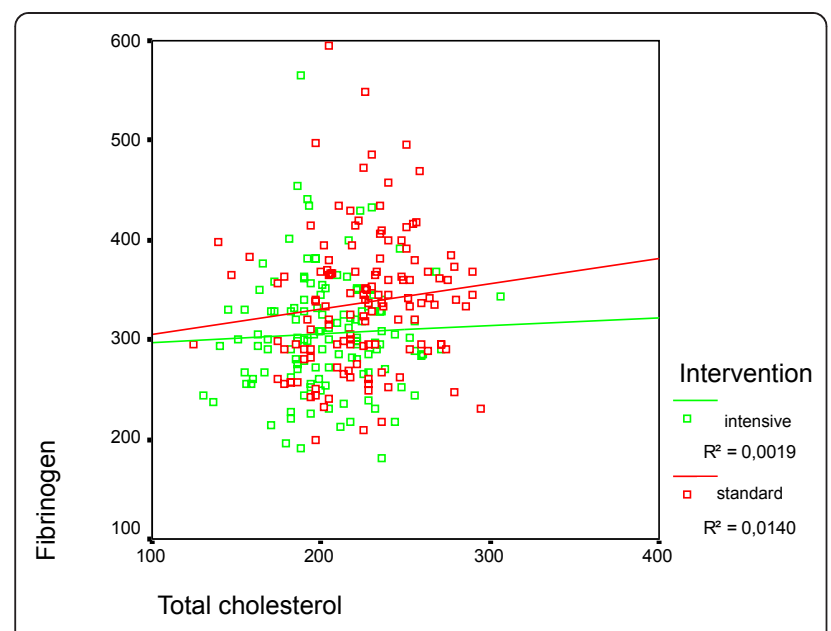

Figure 2 Relationship between Fibrinogen and final cholesterol study according to the type of intervention. cardiovascular factors: Fibrinogen, total cholesterol, SBP, DBP and BMI. The effect of the intensive intervention in the fibrinogen plasma values is not correlated with variations the total cholesterol.

Lifestyle modification might play a role in reducing future cardiovascular events in healthy subjects with hyperfibrinogenemia.

\section{Acknowledgements}

Sources of funding were a grant from the FEA/SEA: 'Fundación y Sociedad Española de

Arteriosclerosis. Investigación clínico-epidemiológica. 2004'.

(http://www.searteriosclerosis.com), and the First Award in the Investigation Projects' from the 'Societat Catalana de Medicina Familiar i Comunitària 2002', (http://www.camfic.cat).

We thank all participating GPs for their cooperation, and Institut Català de la Salut, for the collaboration in the laboratory analysis. We also want to thank to the investigators participant in the EFAP trial:

ABS Florida Sud L'Hospitalet del Llobregat (Barcelona) Juan José Rodríguez Cristóbal, Lluís Gayolà Leuco, José M. Pérez Santos, Ana Aguilar Melgarejo, Francisca Rodríquez Cortés (pshcologist), Teresa González Nogales (nurse), Pere Noe Campderros (nurse), M. José González Burguillos (nurse), Ana 
Grande Froiz (nurse), Domingo Bleda Fernández, Elida Quillama Torres. Florida Nord L'Hospitalet del Llobregat (Barcelona) Raquel Adroer Martori, Luis Solsona Díaz, Antoni Vives Arguilagos, Nuria Sanfeliu Soto, Carmen Delgado Azuara, Celsa Fernández Álvarez (nurse), Elvira Zarza (nurse), Rosa Sorando Alastruey, Carmen Murillo Godoy (nurse). Unidad de trombosis y arteriosclerosis (CSIC), Carlos Alonso-Villaverde Grote, Esther Peña Sendra, Centre d'Investigació Cardiovascular (Institut Català de Ciències

Cardiovasculars) Natalia Tibau Garden, Laboratorio de Análisis Clínicos. Pere Travé Mercadé Laboratorio de Análisis Clínicos.Centro de Atención Primaria Just Oliveras (L'Hospitalet del Llobregat) Centro de Atención Primaria Bon Pastor (Barcelona) Ramón Castelltort Escaler SAP (Servicio de Atención Primaria) L'Hospitalet del LlobregatMartí Julià (Cornellà - Barcelona) Cesar Asenjo Vázquez Sant Feliu de Llobregat-2 (Barcelona) Óscar Fariñas Balaguer, Sebastián Vignoli Carradori, Dolors Llovera Serentill, Jordi Colet Montserrat, Ana Boren Campillo (nurse), Ángeles Jiménez Sánchez (nurse) Bon Pastor (Barcelona) Roser Espona Barri Chafarinas (Barcelona) Montserrat Delgado de la Cruz, Montserrat Carmona (nurse) Río de Janeiro (Barcelona) Montserrat Rodríguez Mas, Pilar Martí de la Morera, Montserrat Alegret Fenoll (nurse), Francisca Benavides Márquez Santa Eulàlia Sud (L'Hospitalet del Llobregat Jordi Monedero Boada, M. Mar Forés Chacón, Rosa Viñas Vidal, [Barcelona]) M. Dolors Riera Cervera, Sònia Sarret Vilà Sant Martí (Barcelona) Ester Maroto Martínez Centre L'Hospitalet del Llobregat (Barcelona) Julia Solé López Les Hortes (Barcelona) Cristina González Viladecans 2 (Barna) Rosa Villafáfila Ferrero, José Luis Bravo, Adela Viniegra Domínguez, M. Carmen García Pulido, Marivi Vivo (nurse).

\section{Author details}

'Medicina, Area Básica Salud Florida Sud, Parc dels Ocellets, L'Hospitalet de Llobregat, Barcelona, Spain. ${ }^{2}$ Institut Català de Ciències Cardiovasculars, Centre Superior d'Investigacions Científiques, Barcelona, Spain. ${ }^{3}$ Laboratorio Analisis Clínicos. Centro Asistencia Primaria Just Oliveras, L'Hospitalet del Llobregat, Barcelona, Spain. ${ }^{4}$ Departamento médico, Abbott Healthcare, Barcelona, Spain. ${ }^{5}$ Unidad de Apoyo a la Investigación, Hospital Clínico San Carlos, Madrid, Spain. ${ }^{6}$ Hospital de Viladecans, Viladecans, Barcelona, Spain.

\section{Authors' contributions}

JJRC formulated the research question, designed the study and supervised its conduct together with CAV, PTM, and JMPS. CFP has done the statistical analysis of the EFAP research program. EPS has been working in the patients database. AML and DBF have been involved in the English version of the manuscript. All the authors approved the final manuscript.

\section{Competing interests}

AML acts as a scientific advisor for Abbott Healthcare, SA. All other authors declare that they have no competing interest.

Received: 5 July 2011 Accepted: 1 March 2012 Published: 1 March 2012

\section{References}

1. Rodríguez Cristóbal JJ, Villaverde Grote CA, Flor Serra F, Travé Mercadé P, Pérez Santos JM, Peña Sendra E, en representación del grupo EFAP: Ensayo clínico de intervención en pacientes con hiperfibrinogenemia en prevención primaria de enfermedad cardiovascular en el ámbito de la atención primaria de salud. Clin Invet Arterioscl 2008, 20:102-9.

2. Ernst $E$, Resch KL: Fibrinogen as cardiovascular risk factor: a meta-analysis and review of the literature. Ann Intern Med 1993, 118:956-63.

3. Kannel WB: Overview of hemostatic factors involved in atherosclerotic cardiovascular disease. Lipid 2005, 40:1215-20.

4. Dotevall A, Johansson S, Wilhelmsen L: Associaton between fibrinogen and other risk factor for cardiovascular disease in men and women. Results from the Goteborg MONICA survey 1985. Ann Epidemiol 1994, 4:369-74.

5. Ernst $E$, Resch $\mathrm{KL}$ : Therapeutic interventions to lower plasma fibrinogen concentration. Eur Heart J 1995, 16(Suppl A):S47-53.

6. Danesh J, Collins R, Appleby P, Peto R: Association of fibrinogen, Creactive protein, albumin, or leukocyte count with coronary heart disease: meta-analyses of prospective studies. JAMA 1998, 279:1477-82.

7. Masiá R, Pena A, Marrugat J, Sala J, Vila J, Pavesi M, Covas M, Aubó C, Elosua R: High prevalence of cardiovascular risk factors in Gerona, Spain, a province with low myocardial infarction incidence. REGICOR Investigators. J Epidemiol Community Health 1998, 52:707-15.
8. Gil B, Avilés J, Maldonado A, Fernández M: Factores de riesgo en ancianos. Estudio de 143 cientes. An Med Intern (Madrid) 1997, 14:495-9.

9. Rodríguez JJ, Villaverde CA, Torelló L, Trocho C, Tibau N, Villaverde AA: Relationship between cholesterol and fibrinogen in primary-care areas. 15 the Wonca World Conference. 1998, 78.

10. Rodríguez Cristóbal JJ, Villaverde Grote CA, Tibau Llardén N, Juan Babot O, Andrades Corrales A, Peña Sendra E: Relationship between cholesterol and fibrinogen in two populations of different geographical location of Catalonia. Rev Clin Esp 2004, 204:405-9.

11. Yano K, Grove J, Chen R, Rodríguez BL, Curb JD, Tracy RP: Plasma fibrinogen as a predictor of total and cause-specific mortality in elderly Japanese-American men. Arterio Throm Vascul Biol 2001, 21:1065-70.

12. Wood D, De Backer G, Faergeman O, Graham I, Mancia G, Pyörälä K: Prevention of coronary heart disease in clinical practice. Summary of recommendations the second joint task force of European and other societies on coronary prevention. Blood Press 1998, 5-6:262-9.

13. Kannel WB: Influence of fibrinogen on cardiovascular disease. Drugs 1997, 54(Suppl 3):S32-40.

14. Rodríguez Cristóbal JJ, Benavides Márquez F, Villaverde Grote C, Peña Sendra E, Flor Serra F, Travé Mercadé P, EFAP Group: Randomised clinical trial of an intensive intervention into life-styles of patients with hyperfibrinogenaemia in primary prevention of cardiovascular pathology in primary health care. Aten Primaria 2005, 35:260-4.

15. Sociedad Española para el Estudio de la Obesidad (SEEDO): Consenso SEEDO'2000 para la evaluación del sobrepeso y la obesidad y el establecimiento de criterios de intervención terapéutica. Med Clin (Barc) 2000, 115:587-597.

16. Maiques A, Villar F, Brotons C, Torcal J, Orozco-Beltran D, Navarro P, LobosBejarano JM, Banegas B, Ortega S, Gil G, Solana S: Recomendaciones preventivas cardiovasculares en atención primaria. Grupo de expertos del PAPPS. Aten Primaria 2007, 39(Suppl 3):15-26.

17. Woolf S, Jonas S, Lawrence R: Health Promotion and Disease Prevention in Clinical Practice Baltimore: Williams \& Wilkins; 1996, 177-223.

18. Medrano MJ, Cerrato E, Boix R, Delgado-Rodríguez M: Factores de riesgo cardiovascular en la población española: metaanálisis de estudios transversales. Med Clin (Barc) 2005, 124:606-12.

19. Wadden TA, Berkowitz R, Womble LG, Sarwer DB, Phelan S, Cato RK, Hesson LA, Osei SY, Kaplan R, Stunkard AJ: Randomized trial of lifestyle modification and pharmacotherapy for obesity. N Engl J Med 2005, 353:2111-20.

20. Shaw K, O'Rourke P, Del Mar C, Kenardy J: Intervenciones psicológicas para el sobrepeso o la obesidad (Revisión Cochrane). The Cochrane Library 2005, 4[http://www.update-software.com].

21. Steptoe A, Kerry S, Rink E, Hilton S: The impact of behavioral counseling on stage of change in fat intake, physical activity, and cigarette smoking in adults at increased risk of coronary heart disease. Am J Public Health 2001, 91:265-9.

22. Sans S, Fitzgerald AP, Royo D, Conroy R, Gram I: Calibración de la tabla SCORE de riesgo cardiovascular para España. Rev Esp Cardiol 2007, 60:476-85.

23. Marrugat J, Subirana I, Comín E, Cabezas C, Vila J, Elosua R, Nam BH, Ramos R, Sala J, Solanas P, Cordón F, Gené-Badia J, D'Agostino RB, VERIFICA Investigators: Validity of an adaptation of the Framingham cardiovascular risk function: the VERIFICA Study. J Epidemiol Community Health 2007, 61:40-7.

doi:10.1186/1756-0500-5-126

Cite this article as: José Rodríguez Cristóbal et al:: Randomised clinical trial of an intensive intervention in the primary care setting of patients with high plasma fibrinogen in the primary prevention of cardiovascular disease. BMC Research Notes 2012 5:126. 